\section{Epidemiologic and clinicopathologic aspects of Leprosy in Dakar; evaluation of 73 new cases}

\author{
Suzanne Oumou Niang,' Moussa Diallo,' \\ Maodo Ndiaye, ${ }^{1}$ Assane Diop, ${ }^{1}$ \\ Boubacar Ahy Diatta, 'Mohamed Wadih,' \\ Assane Kane,' Mame Thierno Dieng,' \\ Charles Insa Badiane ${ }^{2}$ \\ 'Centre Hospitalier Universitaire Aristide \\ Le Dantec, Dakar, Senegal; \\ Institut de Léprologie Appliquée \\ de Dakar, Senegal
}

\section{Abstract}

Hundreds of new leprosy cases are still diagnosed in Dakar despite all the efforts in the struggle by the national program for elimination of leprosy by the Institute of Applied Leprosy in Dakar. The aim of our study was to evaluate the epidemiological, clinicopathological and outcome of new cases of leprosy. A prospective study was conducted over a period of one year listing all new cases of leprosy based on clinical diagnosis, bacteriology and histology. 73 new cases were recorded. The sex ratio was 1.5 and the mean age of 39.5 years. Children aged from 0 to 15 years old represented $12 \%$. The clinical forms were rated in order of decreasing frequency Borderline 47.94\%, 30.13\% lepromatous lepromatous, indeterminate 8.21 , borderline lepromatous 6.84 , TT: 5.47\%, 1.36 and neurological bb\%. Neurological signs were enlarged nerve in 50 cases, a neurological deficit in 16 cases and a sensitive deficit in 16 cases. The complications were burns and ulcerations in 10 cases, a claw in 7 cases, a reversal reaction in 7 cases, erythema nodosum in 4 cases and neuritis in 8 cases. The number of new cases mutilated was $24.65 \%$. The smear was positive in $42 \%$ and histology contribution in $91.37 \%$ of cases. Our study highlights the significant number of patients with multibacillary contagious, affected children, the high proportion of disability grade $2 / 0 M S$ reflecting the delay in diagnosis. This delay is due to ignorance, to traditional treatments and low socio-economic status and lack of trained diagnostic teams in different areas apart from referral centres.

\section{Introduction}

Although leprosy does not constitute a public health problem in Senegal since 1995, it still persists. Each year, hundreds of patients are diagnosed by the staff of the National Program for Elimination of Leprosy (NPEL) and the Institute of Applied Leprology of Dakar (IALD). In 2006, there were 353 new cases of leprosy and 282 in $2007^{1}$ in the whole territory of Senegal. The aim of our study was to evaluate the epidemiological and clinicopathological profile and the outcome of new cases of leprosy in Dakar, the capital of Senegal.

\section{Materials and Methods}

We undertook this prospective study including patients diagnosed with new cases of leprosy during 2008 and being treated at the IALD. The diagnosis was based on clinical, bacteriological (slit skin smear (SSS) of at least 3 sites, accounting for the Bacteriological and morphological index, BI, MI) and pathology criteria (the skin biopsy or the musculocutaneous nerve of the elbow). Riedley \& Jopling classification was used and added to the Pure Neurological Leprosy (PNL). A thorough neurological exam allowed us to classify the patients following the disability criteria of the WHO (World Health Organization).

The WHO treatment protocol was used: the standard multidrug therapy (MDT) for 12 months if Multi-bacillary (MB) leprosy when the IB was positive and multidrug therapy (MDT) for 6 months if Pauci-bacillary (PB) leprosy when the IB was negative. The systemic corticosteroids were prescribed for a period of 6 months in case of severe reactions or recent neuropathy. A secondary prevention of disabilities, with information, education and communication and physical therapy, proper footwear and measures of self protection was set up. Restorative Surgery like nerve decompression, palliative surgery or wound debridement, when necessary completed this global care. A dermatological and neurological exam was done every month during their regular follow up visits.

\section{Results}

\section{Epidemiology}

During the study period, 73 new leprosy patients were registered,they were referred from different centers (Table 1). Thirty-three patients (45.2\%) initially used traditional medicine. Patients comprised 44 men and 29 women with a sex ratio of 1.5. Distribution by age is shown in Figure 1. The mean age of patients was 39.5 and ranged from 4 (Figure 2) to 75 years (Figure 3 ) (mean 39.5).

38 patients (52.05\%) were single versus 35
Correspondence: Suzanne Oumou Niang, Centre Hospitalier Universitaire Aristide Le Dantec, 30 Avenue Pasteur B.P. 3001 Dakar, Senegal.

E-mail: suzeoumou@yahoo.com

Key words: leprosy, Senegal.

Received for publication: 7 June 2011.

Revision received: 3 August 2011.

Accepted for publication: 6 August 2011.

This work is licensed under a Creative Commons Attribution NonCommercial 3.0 License (CC BYNC 3.0).

(C)Copyright S.O. Niang et al., 2011

Licensee PAGEPress, Italy

Dermatology Reports 2011; 3:e18

doi:10.4081/dr.2011.e18

patients $(47.94 \%)$ were married. 38 patients (52.05\%) worked in the informal sector, 8 patients (10.95) in the formal sector. Thirteen patients (17.80\%) were students or pupils and 14 patients (19.80\%) were unemployed. Forty patients (56.16\%) were from Dakar and its suburbs, 32 patients (43.83\%) from other regions of Senegal and 3 patients (4.10\%) from neighboring countries.

\section{Clinicopathological data}

Present complaints were dermatological and neurological symptoms. Seventy-two patients (98.63\%) presented dermatological complains; with spots in 64 patients (84.67\%) and sores in 16 patients (21.91\%); 23 patients (31.5\%) had neurological symptoms with painless burn in 9 patients (12.32\%), ulnar claw in 4 patients (5.47), nerve pain in one patient and paresthesis in 9 patients (12.32\%).

The time of the first visit in relation to appearance of symptoms or signs was variable from less than a year to more than 10 years (Table 2). In 14 patients (19.18\%) there had been a close contact with a leprosy family member. The different clinical presentations are shown on Table 3,41 patients $(56.16 \%)$ had Borderline leprosy, immunologically unstable, while 33 patients $(45.05 \%)$ had the polar leprosy form which is stable. Sixty-three patients $(86.30 \%)$ had normal sensory or hypoesthesic hypochromic macular lesions, 21 patients (28.73\%) had papulo-nodular lesions and 5 patients (6.84\%) had hypo or anesthetic plaques.

Fifty patients (68.49\%) had nerve hypertrophy, cubital nerve in 37 patients (50.68\%); superficial cervical plexus in 7 cases (9.58\%)and superficial peroneal nerve in 6 cases $(8.21 \%), 16$ patients had motor deficit (21.91\%), and 14 patients(19.17\%) had a sensitive deficit. Twenty patients (28.76\%) had nasal obstruction with or without crusted 
rhinitis, and 13 of them (17.80\%) had epistaxis.

Thirty-seven patients (50.68\%) were hospitalized because of complications (Table 4), claw fingers and reversal reactions (Figure 5) were noted in 7 patients each.18 patients (24.65\%) had WHO disability grade 2 at his initial visit. Forty-two(58\%) patients had a negative SSS, and 31 patients (42\%) had a positive one with the BI equal or superior to $4+$ in 5 patients. Biopsies were done in 58 patients (Figure 6) and were conclusive in 53 patients (91.37\%).

At the end, 37 patients (50.6\%) had paucibacillary (PB) leprosy, 30 patients (41.09\%) had multi-bacillary (MB) leprosy. WHO therapeutic standard recommendations were applied to all the patients, except in 5 cases were the BI equal or superior a $4+$, the treatment were conducted for a period of 24 months.

Corticotherapy was given to 29 patients $(39.72 \%)$ who had either neuritis or reaction.40 patients (55\%) suffered from a psychosocial impact, 37 patients (51\%) had some functional impairment and 22 patients (30\%) had some professional impact. Regression of the skin lesions was noted in all the cases after the first month of therapy.

\section{Discussion}

We report 73 new cases of leprosy during a period of one year, this number does not reflect the real situation in the country, because ILAD is a referral center, staffed by Doctors and equipped with a laboratory, while at the NPEL, the diagnosis is done by Leprosy Nurses Specialist LNS, who used the WHO

Table 1. Distribution of cases per referring centers.

\begin{tabular}{lcc}
$\begin{array}{l}\text { Referring } \\
\text { center }\end{array}$ & $\begin{array}{c}\text { Number } \\
\text { of cases }\end{array}$ & $\%$ \\
Hospitals & 40 & 54.78 \\
Health centers & 13 & 17.8 \\
\hline IALD & 12 & 16.43 \\
Private practice & 08 & 10.95 \\
\hline Total & 73 & 100 \\
\hline
\end{tabular}

Table 2. Distribution of cases per timeline of the first visit.

\begin{tabular}{lcc}
$\begin{array}{l}\text { Timeline of } \\
\text { the first visit }\end{array}$ & $\begin{array}{c}\text { Number } \\
\text { of cases }\end{array}$ & $\%$ \\
$<1$ year & 39 & 53.42 \\
1-5 years & 25 & 34.24 \\
\hline $5-10$ years & 07 & 9.58 \\
$>10$ years & 02 & 2.73 \\
\hline
\end{tabular}

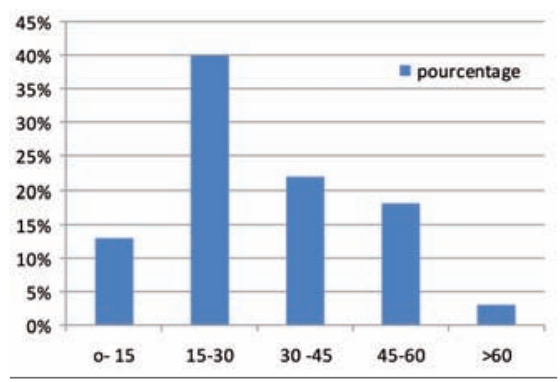

Figure 1. Age distribution of new leprosy cases.

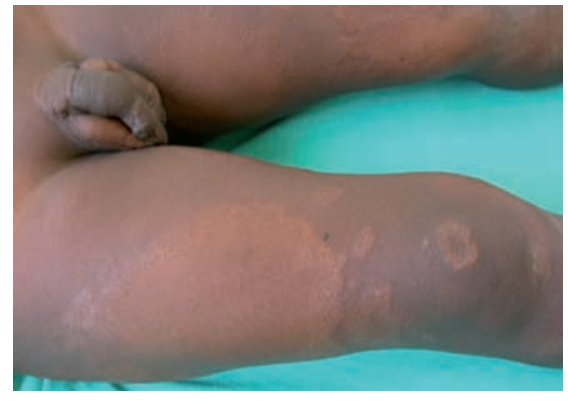

Figure 2. A BT form in a 4-years-old kid.

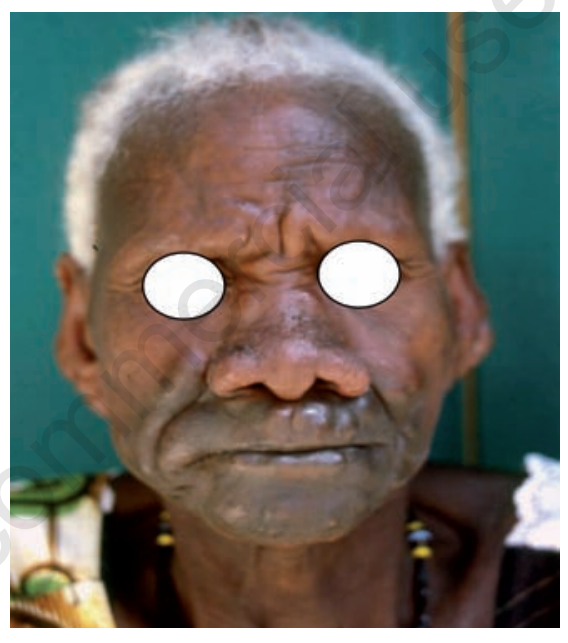

Figure 3. Lepromatous leprosy form in a 70 -years- old woman.

Table 3. Distribution of different leprosy forms.

\begin{tabular}{lccccccc} 
Forms of leprosy & BT & LL & I & BL & TT & PNL & BB \\
Number of cases & 35 & 22 & 6 & 5 & 4 & 1 & 0 \\
Percentage & 47.94 & 30.13 & 8.21 & 6.84 & 5.47 & 1.36 & 0 \\
\hline
\end{tabular}

BT, borderline tuberculoid; LL, lepromatous leprosy; I, Indeterminate leprosy; BL, borderline lepromatous; TT, tuberculoid leprosy; PNL, pure neurological leprosy; BB, borderline borderline.

Table 4. Distribution of cases per complications.

\begin{tabular}{lcc} 
Complication & Number of cases & $\%$ \\
Ulcers or burns of the extremities & 10 & 13.69 \\
Motor deficit & 11 & 15.06 \\
\hline Reversal reaction & 07 & 9.58 \\
Erythema nodusum leprosum & 04 & 5.47 \\
\hline Pure neuritis & 04 & 5.47 \\
Lagophtalmia & 01 & 1.36 \\
\hline
\end{tabular}

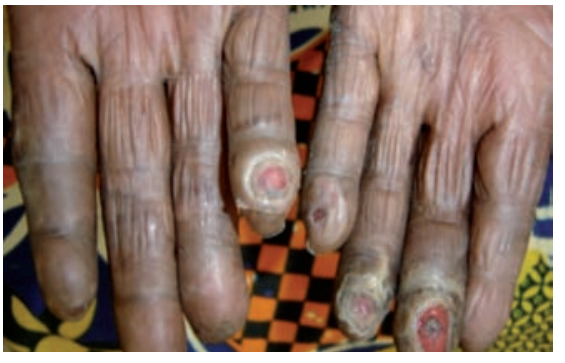

Figure 4. A post burn digital ulcer in $\mathrm{LL}$ patient.

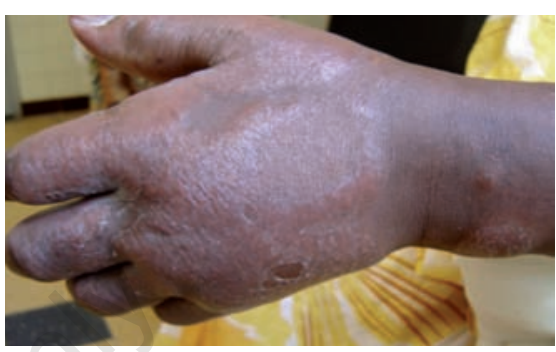

Figure 5. Reverse reaction in a borderline tuberculoid form.

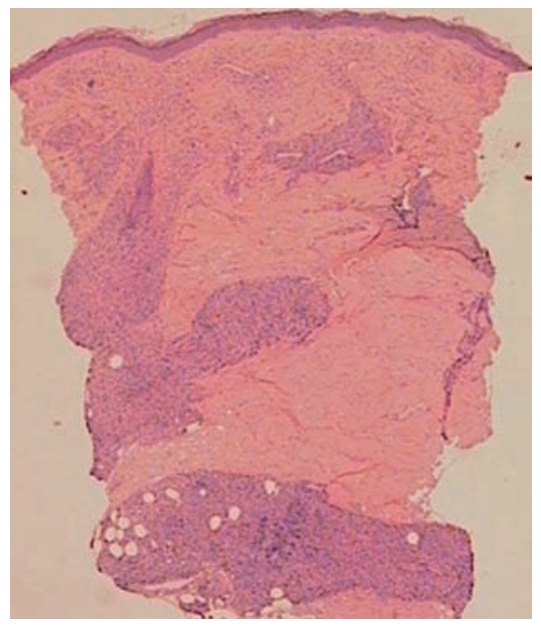

Figure 6. Granulomatous peri-annexial infiltrate in a tuberculoid leprosy. 
clinical classification. The particularities of our study were the relatively large number of Multi-bacillary (MB) leprosy patients, potentially contagious and the number of affected kids, the high proportion of WHO disability grade 2, reflecting late diagnosis and continued transmission of the disease. The limitations of our study were, its short duration, which did not allow a long term outcome. The number of recruited patients represents a quarter of the total new cases of leprosy observed in 2007, in the whole territory of Senegal. Male predominance observed in our study was noted by many other authors ${ }^{2,3,4}$ and the percentage of affected females (39.73\%) matches the one reported by the NPEL, it is less than the $60 \%$ seen in Uganda and far superior to the $8.5 \%$ reported in the Democratic Republic of Congo. ${ }^{1}$ The mean age of 32 years is higher than the one ( 32 years) reported at the Marchoux Institute in Mali. ${ }^{5}$ The time of the first visit was long, more than 1 year in almost half the cases. this delay is certainly due to ignorance, low economic status, but most importantly due to Diagnostic error induced by the use of traditional medicine as we found in $45 \%$ of the cases. the same factors that delayed the diagnosis were also noted by Keita at the Marchoux Institute in Mali, Muller in Guadeloupe. ${ }^{5,6}$ The predominance of interpolar forms $(54.75 \%)$ is similar to the one reported in the literature, while the indeterminate leprosy $(8.22 \%)$ stays inferior to that as reported by Bobin and Flageul evaluated between 20 and $80 \%,{ }^{2,3}$ and can translate also the lack of early diagnosis. The positive SSS in $42 \%$ underline the significant presence of the bacteria as reported in other studies.,7,8

The pathology was very contributory because it confirmed the diagnosis in $91.37 \%$ of the cases. In the case where the histological study was unavailable or non contributory and the SSS negative (27.39\%), the diagnosis was based only on clinical arguments (27.39\%). The number of disabilities reported in our study (24.65\%) reflects the severity of the neurological involvement that is 2 times higher than the NPEL (11.3\%) and the WHO (12.46\%).

\section{Conclusions}

The diagnosis of hundreds of new annual cases of leprosy, and the severity of the neurological impairment justify more vigilance in the primary prevention of the disease. It makes it essential to early diagnosis in order to prevent disabilities. Such struggle includes training highly competent health staff in both Hospitals and community clinics.

\section{References}

1. OMS. Comité Régional de L’Afrique. Elimination de la lèpre. Rapport de situation. AFR/RC57/INF.Doc/2:5 avril 2007.

2. Bobin P. Lèpre. Encycl Méd. Chir. Maladies infectieuses 8-038-F-10,2007.

3. Flageul B. Maladie de Hansen. Lèpre. Encycl Méd Chir. Dermatologie 98-370-A-10,2001.

4. Keita S, Faye 0, Konare HD, Sow SO, Ndiaye HT, Traore I. Evaluation de la classification clinique des nouveaux cas. Etude réalisée à l'Institut Marchoux (Bamako, Mali). Ann Dermatol Venereol 2003;130:184-6.

5. Keita S, Tiendrebeogo A, Berthé D, Faye 0 , Ndiaye HT. Valeur prédictive des motifs de consultation pour le diagnostic de lèpre à Bamako (Mali). Ann Dermatol Venereol 2002;129:1009-11.

6. Muller P, Frederic M, Salzer B, Strobel M. Lèpre en Guadeloupe: maladie en decline, délai diagnostic en hausse. Ann Dermatol Venereol 2003;130:619-21.

7. Bobin P. Peut-on envisager l'élimination de la lèpre dans le monde? Ann Dermatol Venereol 2001;128:205-6.

8. Kadji F, Lucht F, Helenon R, Leoture A. Epidemiologie de la lèpre en Martinique. Bull ALLF 2001;8:19-23. 